\title{
Diabetic Foot in Algeria
}

\author{
Nadia Boudjenah* \\ General Surgeon, Diabetic Foot Surgeon, Diabetic Foot center, Algiers, Algeria
}

*Corresponding author: Nadia Boudjenah, General Surgeon, Diabetic Foot Surgeon, Diabetic Foot center, Algiers, 132 Route Outed Fayet, Amara, Cheraga, Algiers 16003, Algeria, Tel: +213 6618900 17; +33 6815998 00; E-mail: drboudjenah@yahoo.fr

Received: 02 Mar, 2020 | Accepted: 06 Apr, 2020 | Published: 14 Apr, 2020

Citation: Boudjenah N (2020) Diabetic Foot in Algeria. Int J Endocrinol Metab Disord 6(1): dx.doi.org/10.16966/2380-548X.165

Copyright: (c) 2020, Boudjenah N. This is an open-access article distributed under the terms of the Creative Commons Attribution License, which permits unrestricted use, distribution, and reproduction in any medium, provided the original author and source are credited.

\section{Introduction}

We are bringing to you our experience of the diabetic foot in our center in Algiers. After having taken care of more than 60.000 patients over 10 years, we were able to clearly define specific particularities as well as strong points of our therapeutic strategy.

\section{Particularities}

- The fact that we are a private practice specializing in the treatment of diabetic foot, most of our patients come to us as the last resort after having visited most if not all of the public healthcare facilities in the country. Therefore, we are regularly struck by the severity of the lesions.

- We do not have vascular surgery available at our level.

- And to finish, we are facing a population that categorically refuses amputation, which causes a lot of problems regarding the expected functional results.

\section{Three strong points}

1) Therapeutic: we use Carbomedtherapy (carbon dioxide therapy).

2) Economic: It is an outpatient practice; our patients do not have any insurance coverage.

3) Good results: we have less than $0,5 \%$ of major amputations.

\section{Classification Issues}

The biggest problem we face is that we cannot apply any of the known classifications below to our patients:

Fontaine; Rutherford; Wagner; University of Texas Diabetic Wound Classification; WIFI.

Why? For the simple reason that we must take into account several factors:

1) The general health conditions of the patient at arrival
2) The existence of comorbidities and their treatment

3) The existence of local complications: Edema - Charcot foot Venous Thrombosis on the leg axe - and, micro thrombosis due to the septic embolism posing the problem of the benefit of a surgical revascularization; and finally the wound seat that conditions the amputation (Malleolus or foot neck brings us to diagnose an amputation out of hand).

\section{Our solution}

So, as simplistic as it sounds, we have decided to classify our patients into two groups: (an evolutive classification taking into account all factors): a) Those who respond to treatments; b) Those who do not respond to treatments [1-5].

After a treatment period of 8 to 15 days, depending on the severity of the illness, the decision to amputate is made. This action is only carried out after agreement of the patient and his family. It is necessary to take into account the psychological state of the patient and, in particular, not to hide anything from him as to the possible evolution. Therefore, and regarding what we live in our country, we cannot align ourselves with the recommendations of other countries.

\section{What about our Therapeutic Strategy?}

We will quickly go over all the assessments that we request, and which are conventional. Different tests: Blood, Bacteriological, Arterial and venous echo-Doppler, Radiology, and Electroneuromyogram.

\section{As treatment}

We use antibiotic treatments, of course targeted, as well as anticoagulants. Full discharge of the wound is mandatory. It is accompanied by a specific physical activity that has for goal not to lose muscles and joints, and fight against the development of pressure sores. For local treatment, we recommend foot baths with a mixture of water and hydrogen peroxide. Every day, we cover the wounds with a cream Belcic ${ }^{\star}$, and complete with a light dressing which is made by compresses and gauze bands. The rehydration of the feet is ensured 
by coconut, a locally made cream. For mycoses, we use Belmyc ${ }^{\star}$ drops and Belmyc spray.

\section{So, what is CDT?}

The carbon dioxide therapy is called Carbomedtherapy for diseases, and carboxytherapy for aesthetics. The CDT consists of transcutaneous injections of carbon dioxide. This technic was first practiced, in 1932, by Dr Barrieu, at Royat-Chamalières, France. Initially the indications were purely vascular especially for Raynaud's syndrome, arteriopathy of the lower limbs, leg ulcers, and of course, in the care of the diabetic foot. It saw its development intensify when aesthetic doctors discovered its benefits.

\section{CDT indications for diabetics:}

Diabetic foot: we have two separate tables

1) Patients with wounds

2) Patients without wounds, but with vascular or neurological disease. Very often, unfortunately, these aspects are simultaneously entangled.

Diabesity: to reduce fat; to treat the skin: stretch marks, looseness.

\section{How to inject?}

We use a device called CDT evolution. This device delivers heated carbon dioxide during the injections through disposable accessories: $13 \mathrm{~mm}$ and $30 \mathrm{~g}$ Mesotherapy needles, and sterile tubing. The device being preprogrammed, we use the vascular program, that is to say the one which delivers $80 \mathrm{cc}$ of $\mathrm{C}_{2}$ per minute. The injections are transcutaneous and avoid well the vessels. We inject the surface of the 2 lower limbs, from the Scarpa triangle, around and on the wounds, and in the upper limbs in case of neuropathy. It is an outpatient practice. The rhythm of the sessions will depend on the severity of the case: once a week, bimonthly, or monthly.

\section{How does it work?}

Hemoglobin molecules have 4 oxygen molecules at saturation. When we inject carbon dioxide, an exchange takes place between these oxygen molecules and those of $\mathrm{CO}_{2}$. This phenomenon is described as Bohr Effect [Figure 1].

We were able to record the instant nature of this exchange, by measuring $\mathrm{PCO}_{2}$ and $\mathrm{PO}_{2}$, during a $\mathrm{CO}_{2}$ injection. What we found was that the $\mathrm{PCO}_{2}$ measurement curve has not been changed while the $\mathrm{PO}_{2}$ curve recorded an elevation.

\section{What are the benefits?}

On the vascular level: An improvement for faster healing of the wounds and improvement of a walking perimeter.

On the neurological level: Repair of vasa nervorum leads to neurological regeneration which allows a reduction or even disappearance of pain, tingling and nimbless. The recovery of plantar sensitivity, which is very important when it comes to injury prevention.

\section{What are the contraindications?}

As a precaution, women who are pregnant. By obligation, patients with an imbalance of tares, especially respiratory and cardiac; Patients who had a recent acute stroke; Patients with active cancers and active viral infections; finally, with anaerobic germ infections. These situations can be reversed.

\section{What are the side effects?}

They are benign and above all reversible. There are superficial micro-hematomas at the injection points, which can sometimes
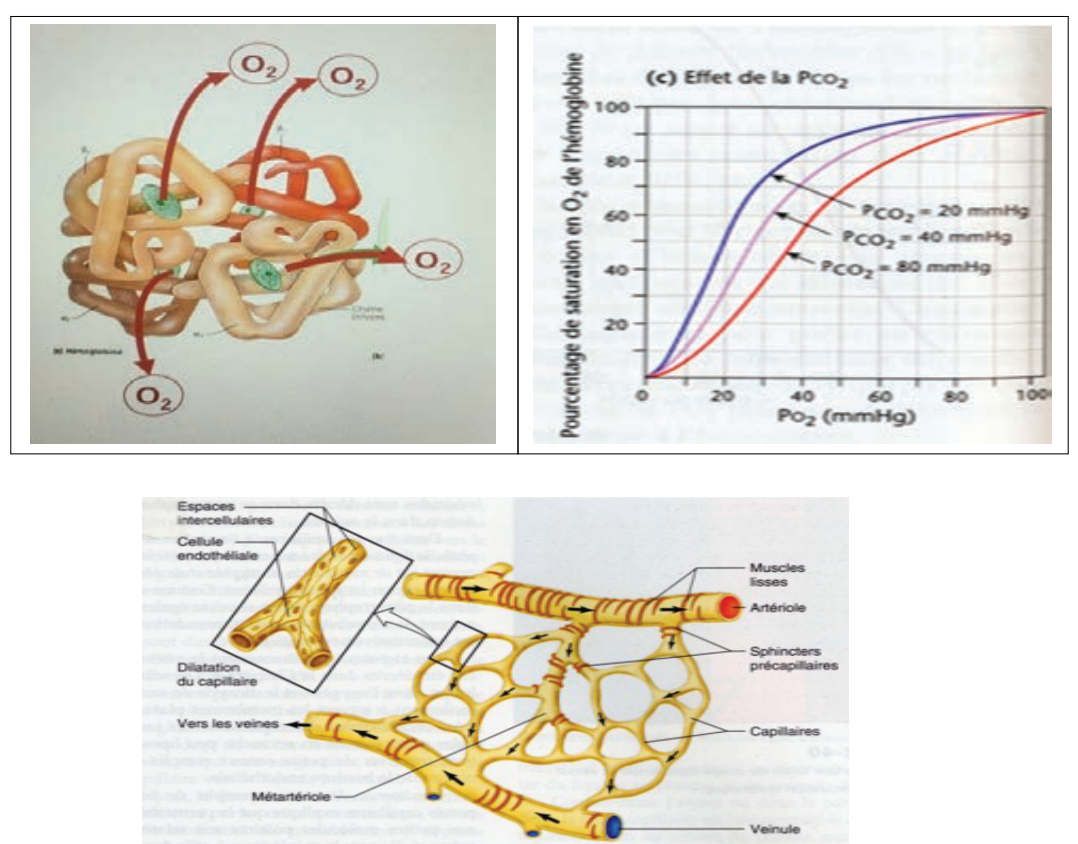

Figure 1: Otherwise, $\mathrm{CO}_{2}$ acts as a vasodilator on the pre-capillary sphincters, transforming silent zones into functional vascular zones. This is what we call false angiogenesis.

This action is perpetuated by the repetition of the sessions by a real angiogenesis. So, there is an influx of blood. At the cellular level, exchanges become more important. There is more oxygen and more nutrients. 

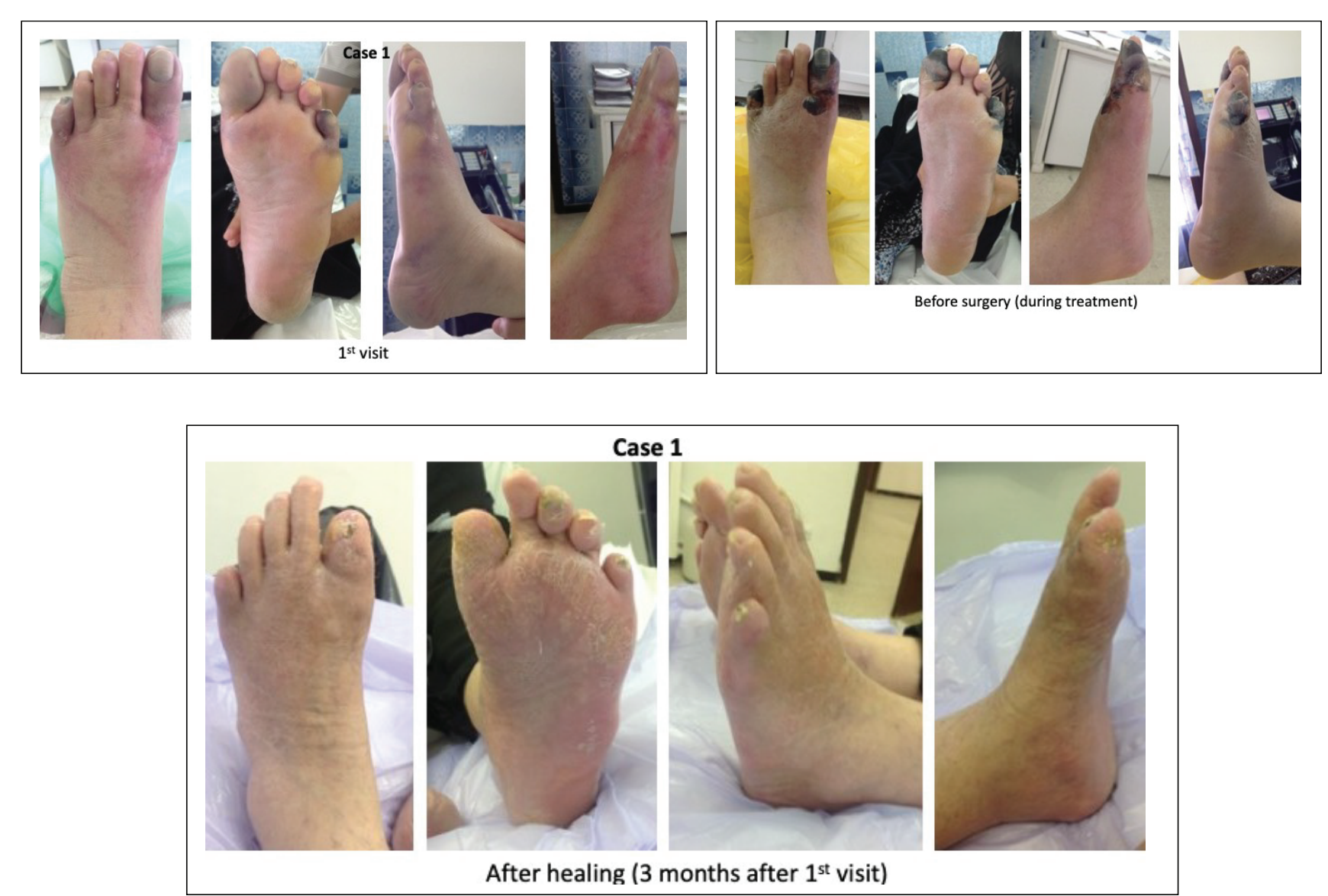

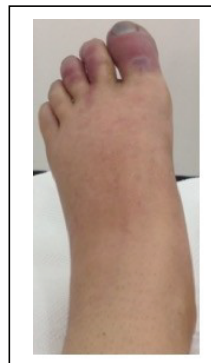

Day 1

Case 2

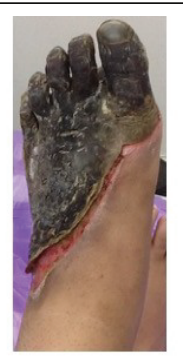

Before surgery
(2 months)

CDT + surger

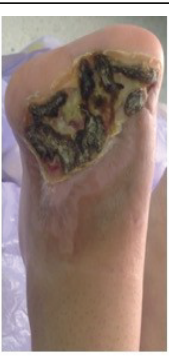

After Surgery

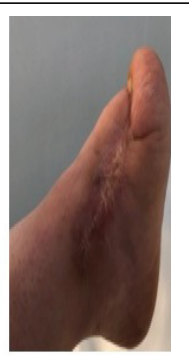

After healing
(5 months)
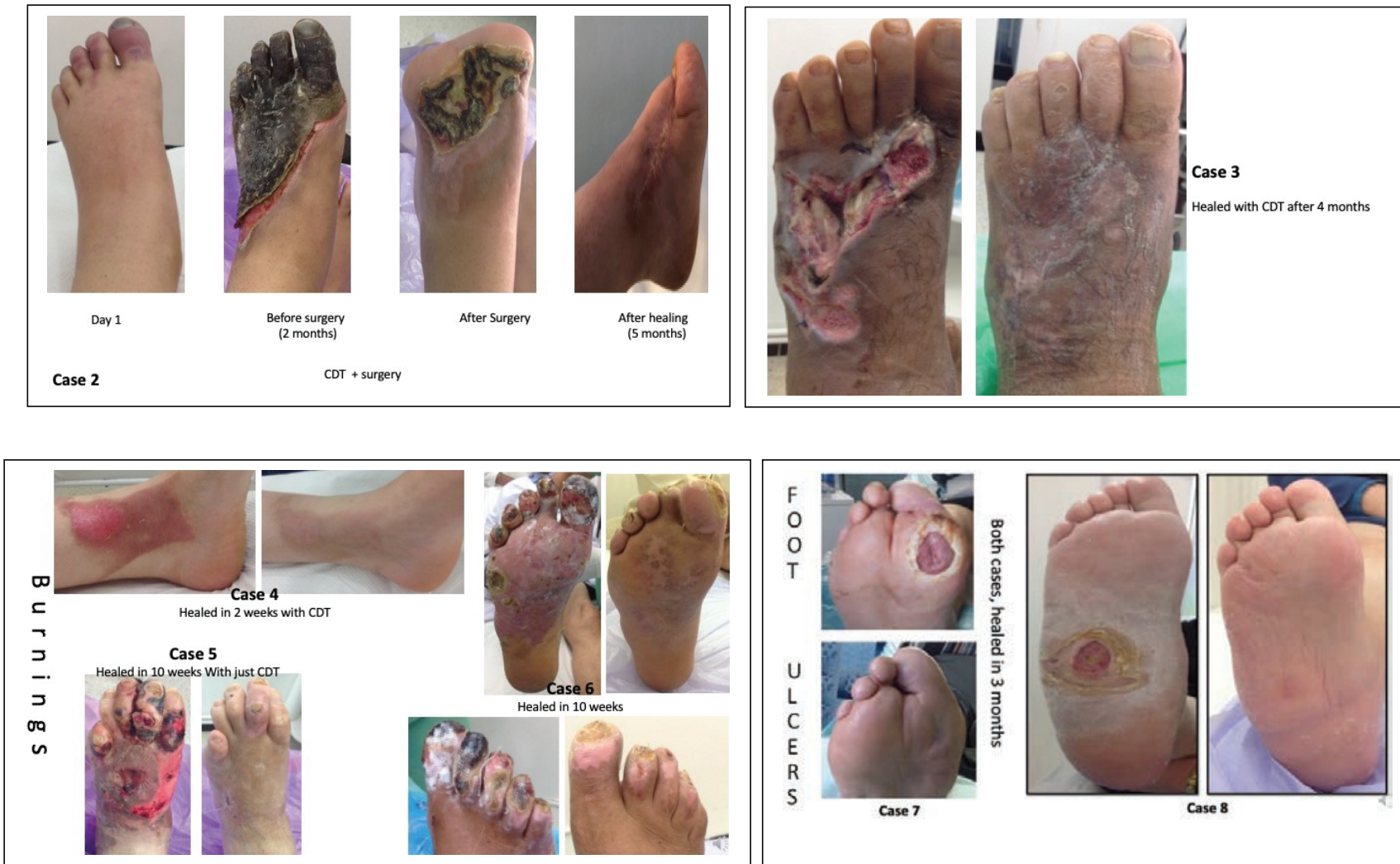

Figure 2: Some pictures of the study. 
follow a session especially if the patient is frankly de-coagulated. They disappear quickly and are not painful. There is no risk of gas embolism. The $\mathrm{CO}_{2}$ pressures delivered by this machine are adjusted to avoid this problem even during accidental injection. The risks of infection should not exist. It is a simple matter of hygiene.

\section{Association to surgery}

Carbomedtherapy significantly improves vascularity. It repels ischemia and distinguishes necrotic from viable areas. We do not remove the necrosis so as not to deepen the lesions and thus obtain a well vascularized floor to perform a skin graft at the same time [6-10].

In post-surgery, the contribution of CDT to wound healing is undeniable. However, the addition of Altrazeal powder and Belcic cream contribute to rapid healing.

It is clear that in our understanding of the diabetic foot, there is no emergency to amputate. The rebalancing of diabetes and tares, the antibiotic treatments adapted by the systematic realization of an antibiogram, and the anticoagulant treatments alone improve the condition of the patient and his wound. The most important thing is to keep trying in order to avoid an amputation.

\section{Results}

Over the period of 10 years, more than 60.000 patients have been handled in our center. From October $1^{\text {st }}, 2018$ to September $30^{\text {th }}, 2019$, we received 7086 new patients:

- For 180 of them, an amputation has been fully indicated from first visit.

- $\quad$ After a preparatory period varying between 1 and 2 months, 160 patients have benefited from surgery with a skin graft in $75 \%$ of the cases.

- We regret 3 deaths during the 1 st month post-surgery for metabolic imbalance and cardiac complications.

- We had to re-operate on 8 patients.

- We did 5 amputations.

- 12 patients have been amputated because of non-control of vascular disease.

- No patients have been amputated for infectious reasons.

$87 \%$ of the patients we received did come with an indication to amputate, diagnosed by other surgeons. $30 \%$ of the patients did not have wounds. We treated them for diabetic neuropathy including carpal and tarsal tunnel lesions, and arteriopathy. The healing time does not matter for our patients as well as the functional results, but moral comfort is important thus improving their quality of life. Some pictures [Figure 2].

\section{Discussion and Conclusion}

The safety and efficiency of Carbomedtherapy make this simple technique an appreciable tool, especially since

a) It is performed on an outpatient practice reducing the cost of the treatment

b) Wound prevention by treating the neuropathy allowing a better comfort for our patients

c) Reducing amputation rates to $0.5 \%$.

\section{References}

1. Brandi C, Grimaldi L, Nisi G, Brafa A, Campa A, et al. (2010) The role of carbon dioxide therapy in the treatment of chronic wounds. In Vivo 24: 223-226.

2. Nisi G, Barberi L, Ceccaccio L, Cuomo R, Sisti A, et al. (2015) Effect of repeated subcutaneous injections of carbon dioxide (CO2) on inflammation linked to hypoxia in adipose tissue graft. Eur Rev Med Pharmacol Sci 19: 4501-4506.

3. Fabry R, Monnet P, Schmidt J, Lusson JR, Carpentier PH, et al. (2009) Clinical and microcirculatory effects of transcutaneous $\mathrm{CO} 2$ therapy in intermittent claudication. Randomized double-blind clinical trial with a parallel design. Vasa 38: 213-224.

4. Hartemann A, Lozeron $P(2015)$ Les neuropathies périphériques chez les diabétiques. Janvier-Février 74: 70-73.

5. Diabetic Foot Conference abstracts (2017).

6. Boudjenah N (2016) Diabetes and its Complications. Georgia World Congress Center, Atlanta, USA.

7. Boudjenah N (2016) Introduction of Carbomedtherapy Endocrine Practice. Jacksonville 22: 16 .

8. Boudjenah A (2013) Diabetic feet: contribution of carbomedtherapy. Diab Metab 39: A99.

9. Dr. Jadranka Kovacevic revue-pathologique.org Carboxytherapy approach, wound management. Février 12, 2014.

10. Sinozić T, Kovacević J (2013) Carboxytherapy - supportive therapy in chronic wound treatment. Acta Med Croatica 67 Suppl 1: 137-141. 